\title{
Evaluation of Peripheral Vascular Calcification and Serum Magnesium Level in a Group of Egyptian Hemodialysis Patients
}

\author{
Kamal Okasha ${ }^{\mathrm{a}^{*}}$, Amal El Bendary ${ }^{\mathrm{b}}$, Abdelmonem Mourad $^{\mathrm{c}}$ \\ a. Internal Medicine and b. Clinical Pathology Departments, Tanta University, Tanta, Egypt \\ c. Radiology Department, Assuit Univeristy, Assuit, Egypt
}

\begin{abstract}
Introduction: Vascular calcification is a risk factor for cardiovascular mortality in the general population. It is highly prevalent in end stage renal disease (ESRD) patients. Low magnesium $(\mathrm{Mg})$ levels have been reported to have a strong association with vascular calcification in hemodialysis (HD) patients. The aims of this study were to evaluate the prevalence of vascular calcification and its relation to serum $\mathrm{Mg}$ concentration in a group of Egyptian HD patients.
\end{abstract}

Methods: We studied 65 stable patients undergoing maintenance HD for more than 6 months. Vascular calcification was evaluated using hand roentgenography. Serum $\mathrm{Mg}$, phosphorus, corrected calcium and intact parathyroid hormone (iPTH) levels were compared between patients with and without vascular calcification.

Results: The study included 41 male and 24 female patients, aged 43-70 years. Vascular calcification was present in $38.5 \%$ of the patients. Mean serum $\mathrm{Mg}$ level was $2.88 \pm 0.51 \mathrm{mg} / \mathrm{dl}$. Male gender was more common in patients with vascular calcification, and they had significantly longer HD duration and significantly higher serum phosphorus and iPTH levels. Serum Mg level was significantly lower in patients with vascular calcification $(2.36 \pm 0.26 \mathrm{mg} / \mathrm{dl}$ vs.3.21 $\pm 0.32 \mathrm{mg} / \mathrm{dl}, \mathrm{p}=0.001)$. Serum $\mathrm{Mg}$ concentration remained as independent negative predictor of hand-artery vascular calcification after adjustment for age, gender, duration of HD, serum phosphorus and iPTH levels.

Conclusion: Vascular calcification is common in the study population and is associated with a lower serum $\mathrm{Mg}$ level. High or sustained-normal Mg levels may have a protective role against the development of vascular calcification in HD patients.

\footnotetext{
* Corresponding author; E mail: okasha70@yahoo.com
}

Keywords: hemodialysis; magnesium; renal failure; vascular calcification

\section{The authors declared no conflict of interest}

\section{Introduction}

Coronary artery calcification is an important predictor of cardiovascular mortality in the general population [1-3]. Atherosclerosis and vascular calcification are also associated with left ventricular hypertrophy (LVH) in hemodialysis (HD) patients and are important surrogate markers of cardiovascular mortality [4].

Vascular calcification in chronic renal failure (CRF) patients is characterized by diffuse mineral deposition, occurring predominantly in the media of the vessel, with no relationship to atheromatous plaque formation [5]. It primarily affects the aorta, but plain x-rays often show a characteristic tramline appearance of calcification extending to the peripheral small vessels, a finding confirmed histologically [5].

Among HD patients, arterial calcification density was found to increase with age, duration of hemodialysis, fibrinogen level, and the prescribed dose of calciumbased phosphate binders [6]. It also correlates with duration of hypertension and total duration of renal disease [7]. Vascular calcification in CRF patients is also often associated with intimal proliferation [8], which in turn correlates with hyperparathyroidism and hyperphosphatemia [9], both common in ESRD.

Magnesium $(\mathrm{Mg})$ is the fourth most abundant cation in the body, mainly located within bone and skeletal muscle. Normal serum $\mathrm{Mg}$ level has a narrow range of $1.8-2.8 \mathrm{mg} / \mathrm{dl}$. Approximately $60 \%$ of the total serum $\mathrm{Mg}$ is present as free $\mathrm{Mg}$ ions, the biologically active form. The kidneys play a principal role in $\mathrm{Mg}$ balance in the healthy state. Approximately $70-80 \%$ of plasma $\mathrm{Mg}$ is filtered by the kidney, $95 \%$ of the filtered load of $\mathrm{Mg}$ is reabsorbed, and only 5\% is excreted in the urine. As CRF 
Figure 1: Plain $X$ ray of the hand of a patient in group 1, showing visible calcification (arrows) of the hand arteries distal to the wrist

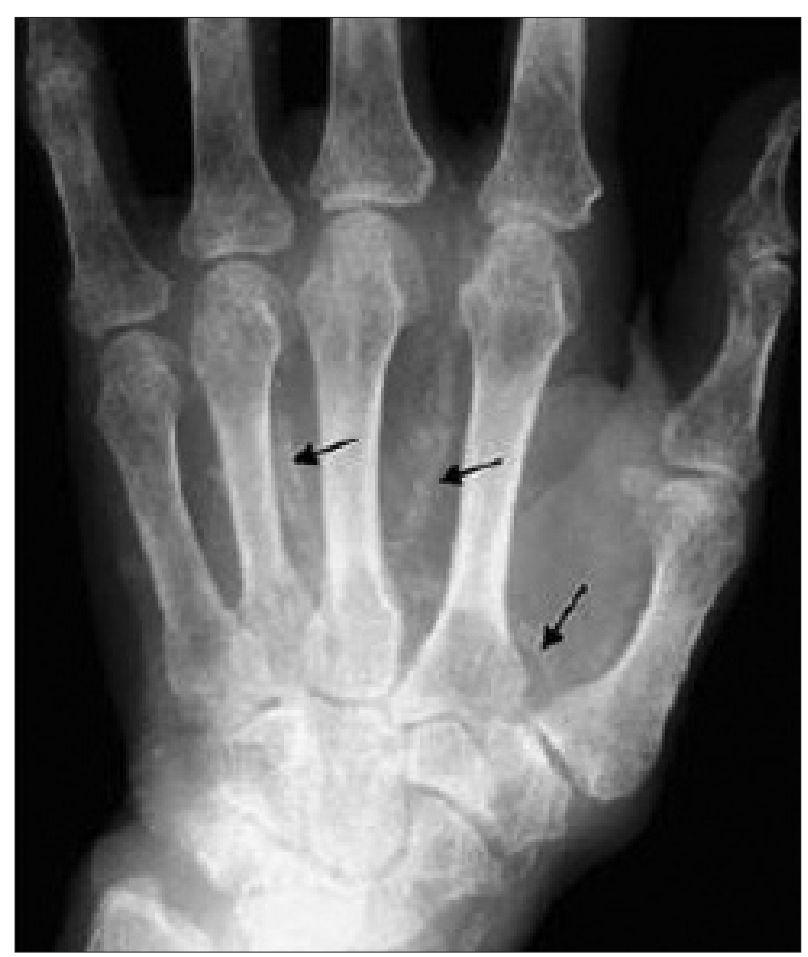

progresses, urinary $\mathrm{Mg}$ excretion may be insufficient to balance intestinal $\mathrm{Mg}$ absorption and dietary $\mathrm{Mg}$ intake becomes a major determinant of serum and total body Mg levels [10].

The serum Mg levels usually remain within normal limits until the glomerular filtration rate (GFR) drops to levels as low as $30 \mathrm{ml} / \mathrm{min}$. At lower GFR levels, serum $\mathrm{Mg}$ level usually increases. Both hyper- and hypomagnesemia have deleterious consequences in CRF patients. Elevated $\mathrm{Mg}$ levels are associated with pruritus, and have potentially harmful effects on nerve conduction velocity, osseous metabolism and parathyroid gland function [11]. Various studies found a significant inverse correlation between serum $\mathrm{Mg}$ and intact parathyroid hormone (iPTH) levels [10]. Undue suppression of iPTH would result in mineralization defects and adynamic bone disease. Low Mg levels have been associated with impairment of myocardial contractility, intra-dialytic hemodynamic instability, and hypotension [11]. There is also evidence suggesting a significant role for hypomagnesemia in the pathogenesis of cardiovascular diseases in HD patients [12].

On the other hand, hypermagnesemia may play a protective role against the development and acceleration of arterial atherosclerosis in patients with chronic renal insufficiency [12], and magnesium supplements may play an important protective role against the progression of atherosclerosis in patients on dialysis [13].

Several studies found a significant inverse relationship between serum $\mathrm{Mg}$ and vascular calcification in HD patients $[12,14,15]$. In this study, we examined serum $\mathrm{Mg}$ levels and peripheral arterial calcification of the hand among a group of Egyptian non-diabetic patients undergoing maintenance HD.

\section{Methods}

We recruited sixty five non-diabetic patients on maintenance HD for this study. All patients were on regular HD for more than 6 months and had no acute illness or malignancy at the time of the study. Patients were dialyzed with synthetic polysulfone membranes and bicarbonate-based dialysate. The electrolytes concentration of dialysate fluid were as follows: sodium $140 \mathrm{mmol} / 1$, potassium $2.0 \mathrm{mmol} / 1$, chloride $120 \mathrm{mmol} / 1$, $\mathrm{Mg} 0.5 \mathrm{mEq} / \mathrm{l}(1.2 \mathrm{mg} / \mathrm{dl})$, bicarbonate $30 \mathrm{mEq} / \mathrm{l}$ and calcium $1.25,1.5$ or $1.75 \mathrm{mmol} / \mathrm{l}$ according to the serum calcium-phosphate equilibrium. The duration of HD was individually tailored ( $\sim 4$ hours thrice weekly) to control body fluids and blood chemistries and to achieve a Kt/V $>$ 1.2. Each subject gave informed written consent to participate in the study. Hand roentgenography was performed on each patient at a voltage of $45 \mathrm{kV}$. The hand roentgenographs were analyzed by a radiologist and the results were expressed as positive or negative according to the presence or absence of visible vascular calcification of the hand arteries distal to the wrist joints (figure 1).

Eight pre-dialysis non-fasting blood samples were drawn over a four months period prior to roentgenography to measure serum calcium, phosphate, $\mathrm{Mg}$, and albumin levels. Serum calcium levels were corrected according to serum albumin levels. The mean values of these measurements were used for analysis. Serum iPTH was measured once at the time of roentgenography. Kt/V was calculated using the following formula: $\mathrm{Kt} / \mathrm{V}=(0.026 \mathrm{x}$ average urea reduction ratio) -0.46

Continuous variables were expressed as mean \pm SD. Unpaired Student's t-test was used to compare clinical parameters between patients with and without vascular calcification, Chi-squared test was used to compare proportions. Multiple regression analysis was performed to explore the impact of serum $\mathrm{Mg}$ level on vascular calcification. All analyses were performed using SPSS 17.0 for Windows on personal computers. 
Table 1: Demographics and clinical characteristics of the studied patients groups with (group 1) and without (group 2) vascular calcification

\begin{tabular}{|c|c|c|c|}
\hline Demographic and clinical characteristics & Group $1(n=25)$ & Group $2(n=40)$ & P value \\
\hline Age (years, mean $\pm \mathrm{SD}$ ) & $57.2 \pm 6.6$ & $53.9 \pm 7.3$ & 0.07 \\
\hline Male gender $(\%)$ & 64 & 62.5 & $0.04^{*}$ \\
\hline HD duration (months, mean \pm SD) & $36.4 \pm 3.6$ & $22.2 \pm 7.3$ & $0.001^{*}$ \\
\hline Smoking (\%) & 32 & 32.5 & 0.81 \\
\hline Body mass index $(\mathrm{kg} / \mathrm{m} 2$, mean $\pm \mathrm{SD})$ & $21.5 \pm 2.8$ & $20.9 \pm 3.1$ & 0.72 \\
\hline Serum albumin $(g / d l$, mean $\pm S D)$ & $3.5 \pm 0.5$ & $3.6 \pm 0.4$ & 0.68 \\
\hline Serum creatinine $(\mathrm{mg} / \mathrm{dl}$, mean $\pm \mathrm{SD})$ & $10.9 \pm 1.8$ & $10.7 \pm 2.5$ & 0.45 \\
\hline Hematocrit $(\%$, mean $\pm \mathrm{SD})$ & $30.5 \pm 5.1$ & $30.8 \pm 4.5$ & 0.9 \\
\hline Corrected serum calcium $(\mathrm{mg} / \mathrm{dl}$, mean $\pm \mathrm{SD})$ & $9.3 \pm 0.36$ & $9.2 \pm 0.35$ & 0.6 \\
\hline Phosphorus (mg/dl, mean \pm SD) & $6.0 \pm 0.64$ & $4.95 \pm 0.72$ & $0.001^{*}$ \\
\hline $\mathrm{Mg}(\mathrm{mg} / \mathrm{dl}$, mean $\pm \mathrm{SD})$ & $2.36 \pm 0.26$ & $3.21 \pm 0.32$ & $0.001^{*}$ \\
\hline Intact parathyroid hormone $(\mathrm{pg} / \mathrm{ml}$, mean $\pm \mathrm{SD})$ & $270 \pm 45.6$ & $187 \pm 37.5$ & $0.001^{*}$ \\
\hline
\end{tabular}

* statistically significant

\section{Results}

The study included 41 male and 24 female patients, with an age range of 22-77 years (mean $47.5 \pm 15.4$ years). Mean duration on dialysis was $25 \pm 9$ months and mean $\mathrm{Kt} / \mathrm{V}$ was $1.46 \pm 0.13$. Clinical and biochemical profiles of the patients enrolled in the study are shown (Table 1). There were 25 patients (16 males and 9 females) with vascular calcification (group 1) and 40 patients (25 males and 15 females) without vascular calcification (group 2). There were no significant differences in age, smoking index, body mass index, diastolic blood pressure, serum calcium, serum albumin, serum creatinine or Kt/V between the two groups. Male gender was more common in group 1 (vascular calcification), and patients in that group had significantly longer HD duration and significantly higher serum phosphorus and iPTH levels. On the other hand, serum $\mathrm{Mg}$ was significantly lower in group 1.

Multiple regression analysis revealed that serum $\mathrm{Mg}$ concentration remained as an independent negative predictor of hand-artery vascular calcification in HD patients after adjustment for age, gender, duration of HD, serum phosphorus and iPTH level (Table 2).

\section{Discussion}

Radiographic surveys were previously used to evaluate vascular calcification in HD patients [15-18]. For the purpose of this study, vascular calcification was defined by the presence of visible arterial calcification of the hand arteries on plain roentgenographs. This method has limitations in terms of quantitative evaluation of calcification or detection of minute calcification. However, it is easily performed in clinical practice without the need for special equipment such as electron beam computed tomography. Using this method had revealed statistically significant associations between vascular calcification and different clinical parameters [15-18]. Some investigators examining factors affecting vascular calcification in HD patients have emphasized the importance of calcium-phosphate metabolism while neglecting the role of magnesium $[18,19]$. In the present study, serum phosphate levels were significantly higher in patients with vascular calcification compared to those without, in agreement with previous investigations [13, 15, 16, 18, 19]. Furthermore, we found that serum $\mathrm{Mg}$ concentrations were significantly lower in the vascular calcification group, and in multiple regression analysis, lower $\mathrm{Mg}$ concentration remained a significant independent predictor of the presence of vascular calcification after adjustment for other confounding factors, such as phosphate and iPTH. Our results are consistent with the several reports which showed that hypomagnesemia is significantly related to the presence of vascular calcification of the hand arteries, independent of serum phosphate and iPTH levels [13, 15, 16].

Concerning skeletal calcification, hypomagnesemia has been reported to be related to development of chondrocalcinosis in Bartter's, Gateman's and short bowel syndromes [20]. Hypomagnesemia has also been reported to be related to development of ectopic 
Table 2: Risk factors for vascular calcification in HD patients using multiple logistic regression analysis

\begin{tabular}{lll}
\hline Variable & OR & P value \\
\hline Hemodialysis duration & 1.46 & $0.001^{*}$ \\
Male gender & 1.37 & $0.01^{*}$ \\
Intact parathyroid hormone & 1.26 & $0.003^{*}$ \\
Phosphorus & 1.20 & $0.005^{*}$ \\
Age & 1.11 & $0.049^{*}$ \\
Corrected calcium & 1.00 & 0.992 \\
Mg & 0.73 & $0.001^{*}$ \\
\hline
\end{tabular}

* statistically significant

calcification in animal models [21]. In the non-uremic general population, current literature showed strong evidence that hypomagnesemia is significantly associated with cardiovascular disease and atheromatous diseases [1-3]. In HD patients, intracellular and extracellular $\mathrm{Mg}$ has been reported to be negatively correlated with common carotid artery intima-media thickness, suggesting that Mg plays an important protective role in the development and acceleration of arterial atherosclerosis [12]. Serum $\mathrm{Mg}$ was previously reported to be significantly lower in peritoneal dialysis (PD) and HD patients with vascular calcification than in patients without calcification [13, $15,16]$. Low serum $\mathrm{Mg}$ was also reported to be related to a higher prevalence of mitral valve calcification among HD patients [14]. These observations raise the possibility that magnesium supplements may have a role in the prevention of vascluar calcification. An experimental study demonstrated that dietary supplementation with $\mathrm{Mg}$ reduced medial calcification of the grafted aorta in the rat [22]. Potential benefits have also been attributed to $\mathrm{Mg}$ carbonate use as an effective, less toxic and less expensive phosphate binder in HD patients [23].

These findings can be explained in the light of previous research. $\mathrm{Mg}$ acts as a cofactor in numerous enzyme systems, such as alkaline phosphatase, which was demonstrated to be present in the tissue of vascular calcification [24]. Mg concentration may affect alkaline phosphatase activity, leading to modulation of calcification mechanism in $\mathrm{HD}$ patients. $\mathrm{Mg}$ may affect phosphate crystal solubility in synovial fluid and serum $\mathrm{Mg}$ level may affect the development of vascular calcification reported to be closely related with inorganic phosphate [24].

Secondary hyperparathyroidism is frequently associated with soft tissue calcification, including vascular calcification. Wei et al found a significant inverse relationship between serum $\mathrm{Mg}$ and serum $\mathrm{iPTH}$ in HD and PD patients [10]. Navarro et al noted that hypermagnesemia was independently associated with decreased parathyroid hormone in PD patients [25].

Hypermagnesemia may protect against vascular calcification via a decrease in parathyroid hormone levels. In our study, parathyroid hormone levels were significantly higher in patients with vascular calcification, compared to those without calcification. In fact, the mean serum $\mathrm{Mg}$ concentration in the vascular calcification group was $2.36 \pm 0.26 \mathrm{mg} / \mathrm{dl}$, i.e. within the normal reference range for normal subjects without renal failure. Dialysate $\mathrm{Mg}$ plays a critical role in maintaining $\mathrm{Mg}$ homeostasis in HD patients, with serum $\mathrm{Mg}$ being largely dependent on the concentration of the ion in the dialysis solution. We suggest that $\mathrm{Mg}$ concentration of dialysis fluid could be increased above the current concentration of $0.5 \mathrm{mmol} / \mathrm{L}$ $(1.2 \mathrm{mg} / \mathrm{dl})$, with the aim of preventing or reducing vascular calcification in HD patients. However, further studies are required to determine what concentration of serum or dialysate $\mathrm{Mg}$ are optimal for these patients.

\section{Conclusion}

The results of this study confirm previous observations that lower serum $\mathrm{Mg}$ levels are significantly associated with vascular calcification in HD patients, independent of the serum calcium, phosphate and iPTH levels. These results suggest that higher serum $\mathrm{Mg}$ concentrations may have a protective role against vascular calcification in HD patients. Further studies are required to evaluate the role of raising $\mathrm{Mg}$ concentration of dialysis solutions in the context of preventing vascular calcification among HD patients.

\section{References}

1. Margolis JR, Chen JT, Kong Y, Peter RH, Behar VS, Kisslo JA. The diagnostic and prognostic significance of coronary artery calcification. A report of 800 cases. Radiology. 1980 Dec;137(3):609-16.

2. Ma J, FolsomAR, Melnick SL, Eckfeldt JH, SharrettAR, Nabulsi AA, Hutchinson RG, Metcalf PA. Associations of serum and dietary magnesium with cardiovascular disease, hypertension, diabetes, insulin, and carotid arterial wall thickness: the ARIC study. Atherosclerosis Risk in Communities Study. J Clin Epidemiol. 1995 Jul;48(7):927-40.

3. Liao F, Folsom AR, Brancati FL. Is low magnesium concentration a risk factor for coronary heart disease? The Atherosclerosis Risk in Communities (ARIC) Study. Am Heart J. 1998 Sep;136(3):480-90. 
4. Yildiz A, Memisoglu E, Oflaz H, Yazici H, Pusuroglu H, Akkaya V, Erzengin F, Tepe S. Atherosclerosis and vascular calcification are independent predictors of left ventricular hypertrophy in chronic haemodialysis patients. Nephrol Dial Transplant. 2005 Apr;20(4):760-7. Epub 2005 Feb 16.

5. Ejerblad S, Ericsson JLE, Eriksson I. Arterial lesions of the radial artery in uremic patients. Acta Chir Scand. 1979;145:415-28.

6. Guérin AP, London GM, Marchais SJ, Metivier F. Arterial stiffening and vascular calcifications in end-stage renal disease. Nephrol Dial Transplant. 2000 Jul;15(7):1014-21.

7. Ibels LS, Alfrey AC, Huffer WE, Craswell PW, Anderson JT, Weil R 3rd. Arterial calcification and pathology in uremic patients undergoing dialysis. Am J Med. 1979 May;66(5):790-6.

8. Davies MR, Hruska KA. Pathophysiological mechanisms of vascular calcification in end-stage renal disease. Kidney Int. 2001 Aug;60(2):472-9.

9. Nishizawa Y, Shoji T, Kawagishi T, Morii H. Atherosclerosis in uremia: possible roles of hyperparathyroidism and intermediate density lipoprotein accumulation. Kidney Int Suppl. 1997 Nov;62:S90-2.

10. Wei M, Esbaei K, Bargman J, Oreopoulos DG. Relationship between serum magnesium, parathyroid hormone, and vascular calcification in patients on dialysis: a literature review. Perit Dial Int. 2006 MayJun;26(3):366-73.

11. Navarro-González JF, Mora-Fernández C, GarcíaPérez J. Clinical implications of disordered magnesium homeostasis in chronic renal failure and dialysis. Semin Dial. 2009 Jan-Feb;22(1):37-44.

12. Tzanakis I, Virvidakis K, Tsomi A, Mantakas E, Girousis N, Karefyllakis N, Papadaki A, Kallivretakis $\mathrm{N}$, Mountokalakis T. Intra- and extracellular magnesium levels and atheromatosis in haemodialysis patients. Magnes Res. 2004 Jun;17(2):102-8.

13. Turgut F, Kanbay M, Metin MR, Uz E, Akcay A, Covic A. Magnesium supplementation helps to improve carotid intima media thickness in patients on hemodialysis. Int Urol Nephrol. 2008;40(4):1075-82.

14. Tzanakis I, Pras A, Kounali D, Mamali V, Kartsonakis V, Mayopoulou-Symvoulidou D, Kallivretakis N. Mitral annular calcifications in haemodialysis patients: a possible protective role of magnesium. Nephrol Dial Transplant. 1997 Sep;12(9):2036-7.
15. Ishimura E, Okuno S, Kitatani $\mathrm{K}$, Tsuchida $\mathrm{T}$, Yamakawa T, Shioi A, Inaba M, Nishizawa Y. Significant association between the presence of peripheral vascular calcification and lower serum magnesium in hemodialysis patients. Clin Nephrol. 2007 Oct;68(4):222-7.

16. Meema HE, Oreopoulos DG, Rapoport A. Serum magnesium level and arterial calcification in end-stage renal disease. Kidney Int. 1987 Sep;32(3):388-94.

17. Ishimura E, Okuno S, Kitatani K, Maekawa K, Izumotani T, Yamakawa T, Jono S, Shoji T, Shioi A, Inaba M, Massry SG, Nishizawa Y. C-reactive protein is a significant predictor of vascular calcification of both aorta and hand arteries. Semin Nephrol. 2004 Sep;24(5):408-12.

18. Ishimura E, Okuno S, Kitatani K, Kim M, Shoji T, Nakatani T, Inaba M, Nishizawa Y. Different risk factors for peripheral vascular calcification between diabetic and non-diabetic haemodialysis patients: importance of glycaemic control. Diabetologia. 2002 Oct;45(10):1446-8.

19. Goodman WG, Goldin J, Kuizon BD, Yoon C, Gales B, Sider D, Wang Y, Chung J, Emerick A, Greaser L, Elashoff RM, Salusky IB. Coronary-artery calcification in young adults with end-stage renal disease who are undergoing dialysis. N Engl J Med. 2000 May 18;342(20):1478-83.

20. Richette P, Ayoub G, Bardin T, Bouvet S, Orcel P, Badran AM. Hypomagnesemia and chondrocalcinosis in short bowel syndrome. J Rheumatol. 2005 Dec;32(12):2434-6.

21. Schafer C, Heiss A, Schwarz A, Westenfeld R, Ketteler M, Floege J, Muller-Esterl W, Schinke T, JahnenDechent W. The serum protein alpha 2-HeremansSchmid glycoprotein/fetuin-A is a systemically acting inhibitor of ectopic calcification. J Clin Invest. 2003 Aug;112(3):357-66.

22. Schwille PO, Schmiedl A, Schwille R, Brunner P, Kissler H, Cesnjevar R, Gepp H. Media calcification, low erythrocyte magnesium, altered plasma magnesium, and calcium homeostasis following grafting of the thoracic aorta to the infrarenal aorta in the rat: differential preventive effects of long-term oral magnesium supplementation alone and in combination with alkali. Biomed Pharmacother. 2003 Mar;57(2):88-97. 
23. Tzanakis IP, Papadaki AN, Wei M, Kagia S, Spadidakis VV, Kallivretakis NE, Oreopoulos DG. Magnesium carbonate for phosphate control in patients on hemodialysis. A randomized controlled trial. Int Urol Nephrol. 2008;40(1):193-201.

24. Giachelli CM, Jono S, Shioi A, Nishizawa Y, Mori K,
Morii H. Vascular calcification and inorganic phosphate. Am J Kidney Dis. 2001 Oct;38(4 Suppl 1):S34-7.

25. O'Hare AM, Hsu CY, Bacchetti P, Johansen KL. Peripheral vascular disease risk factors among patients undergoing hemodialysis. J Am Soc Nephrol. 2002 Feb;13(2):497-503. 